\title{
Adenovirus-mediated overexpression of interleukin-21 regulates the development of oral squamous cell carcinoma in vitro
}

\author{
HAO LIU ${ }^{1 *}$, PENG LIU ${ }^{2 *}$, DI SUN ${ }^{3}$, DAYUAN XING ${ }^{1}$, XIAOPING WANG $^{1}$, JINGE YANG $^{4}$ and SHENGZHI WANG ${ }^{1}$ \\ Departments of ${ }^{1}$ Stomatology, ${ }^{2}$ Clinical Laboratory, ${ }^{3}$ Pathology and ${ }^{4}$ Emergency, \\ Yantai Yuhuangding Hospital of Qingdao University, Yantai, Shandong 264000, P.R. China
}

Received August 12, 2019; Accepted March 5, 2020

DOI: 10.3892/ol.2020.11822

\begin{abstract}
Interleukin-21 (IL-21) is an important cytokine that is currently being investigated for its potential use in tumor immunotherapy in the future. In tumor cells, IL-21 stimulates the immune response by increasing the cytotoxic activity of natural killer cells, $\mathrm{B}$ cells and $\mathrm{CD}^{+} \mathrm{T}$ cells, which in turn induces the apoptosis of tumor cells. The therapeutic effects of IL-21 have been investigated in several types of disease and numerous clinical trials are in progress. The aim of the present study was to determine the role of IL-21 in oral squamous cell carcinoma (OSCC) in vitro. IL-21 expression was detected in OSCC tissues via RT-qPCR, western blotting and immunohistochemistry analyses. The results demonstrated that IL-21 protein expression decreased in OSCC tissues. IL-21 was overexpressed using adenovirus in CAL-27 cells. The Cell Counting Kit- 8 assay demonstrated that overexpression of IL-21 inhibited cell proliferation. Furthermore, overexpression of IL-21 inhibited cell migration, detected by the wound healing assay, and promoted cell apoptosis, detected by TUNEL staining and flow cytometry analysis. The results demonstrated that overexpression of IL-21 inhibited activation of the JNK signaling pathway. In conclusion, the findings of the present study suggest that IL-21 may function as a potent antitumor agent in OSCC.
\end{abstract}

Correspondence to: Dr Jinge Yang, Department of Emergency, Yantai Yuhuangding Hospital of Qingdao University, 20 Yuhuangding East Road, Yantai, Shandong 264000, P.R. China E-mail: yangjinge7515@126.com

Dr Shengzhi Wang, Department of Stomatology, Yantai Yuhuangding Hospital of Qingdao University, 20 Yuhuangding East Road, Yantai, Shandong 264000, P.R. China

E-mail: wangsz1965@163.com

*Contributed equally

Key words: interleukin-21, oral squamous cell carcinoma, immunotherapy

\section{Introduction}

Oral squamous cell carcinoma (OSCC) is a highly aggressive neoplasm found in the oral and maxillofacial region, with approximately 354,864 new cases and 177,384 deaths in 2018, worldwide (1). The most significant risk factors are smoking and alcohol consumption $(2,3)$. Despite recent advances in cancer treatment, such as surgery, radiotherapy or chemotherapy, the overall five-year survival rate for OSCC remains less than 50\% (4). Therefore, novel therapeutic methods are required to treat this disease. Recently, advances in cancer immunotherapy have made considerable progress. Immunotherapy can be used to manipulate the development of early carcinogenesis, improve the quality of life and extend the patient survival time by improving the antitumor immune functions of the patients (5). Therefore, immunotherapy may be considered an alternative treatment strategy for OSCC.

Interleukin-21 (IL-21) is a member of the $\gamma$ chain cytokine family, which is mainly produced by activated $\mathrm{CD} 4^{+} \mathrm{T}$ cells and natural killer (NK) cells (6). IL-21 can regulate the innate and adaptive immune response, which have been found to serve a diverse range of important roles in inflammation and tumor progression (7). For example, IL-21 can critically regulate $\mathrm{B}$ cell function and amplify NK cell function, and can also regulate potent antitumor activity and facilitate heightened tumor-specific T lymphocyte function (8). Moreover, IL-21 was revealed to stimulate the expansion of $\mathrm{CD}^{+} \mathrm{T}$ cells and increase their cytotoxicity, which in turn promoted the proliferation and antibody production of $\mathrm{T}$ cell-dependent $\mathrm{B}$ cells; this induced the differentiation and activation of NK cells, and reduced the number of Treg cells in tumors $(8,9)$. Previously, the application of recombinant human IL-21 to patients or animals has demonstrated significant antitumor activity in both nonclinical and clinical studies (10-12). Phase I and II clinical trials of IL-21 have been conducted in patients with renal cell carcinoma, non-Hodgkin's lymphoma and malignant melanoma (10-12); the results indicated that the therapeutic administration of IL-21 had a high validity and safety profile in patients (13-15).

Thus, the present study aimed to investigate the expression levels of IL-21 in OSCC tissues and the antitumor effects of IL-21 in CAL-27 cells in vitro. Moreover, the role of IL-21 in OSCC immunotherapy was further determined. 


\section{Materials and methods}

Human OSCC samples. Ethical approval was obtained from the Ethics Committee of the Yantai Yuhuangding Hospital and informed written consent was provided from all patients. None of the patients with OSCC had received any chemotherapy or radiotherapy before excision. OSCC and adjacent normal tissues (positioned $>5 \mathrm{~cm}$ away from the tumor) were obtained from 45 patients with OSCC ( 29 men and 16 women; age range, $42-79$ years; mean age, 59 years) who underwent surgical resection at the Yantai Yuhuangding Hospital between October 2016 and April 2018. All samples were confirmed by pathological examination. The histological grade and tumor stage were assigned according to the World Health Organization (WHO) (16) and the International Union Against Cancer classification system (17).

Reagents. DMEM (cat. no. 11960-044), FBS (cat. no. 12484-010), penicillin-streptomycin (cat. no. 15140-122), TRIzol $^{\circledR}$ reagent (cat. no. 15596-026), rabbit anti-IL-21 polyclonal antibody (cat. no. PA5-34801; 1:1,000), mouse anti- $\beta$-actin monoclonal antibody (cat. no. MA1-744; 1:5,000), horseradish peroxidase (HRP)-conjugated goat anti-mouse IgG antibody (cat. no. 31430; 1:3,000) and HRP-conjugated goat anti-rabbit IgG antibody (cat. no. 31460; 1:3,000) were all obtained from Invitrogen; Thermo Fisher Scientific, Inc. The rabbit anti-cleaved (c)-caspase-3 antibody (cat. no. ab2302; 1:2,000), rabbit anti-Bax antibody (cat. no. ab32503; 1:2,000), rabbit anti-Bcl-2 antibody (cat. no. ab32124; 1:1,000), rabbit anti-JNK1+JNK2+JNK3 antibody (cat. no. ab179461; 1:2,000), rabbit anti-JNK1+JNK2+JNK3 (phospho T183+T183+T221; 1:1,000) antibody (cat. no. ab124956), rabbit anti-AKT1+AKT2+AKT3 antibody (cat. no. ab185633; 1:1,000) and rabbit anti-AKT3 (phospho S472)+AKT2 (phospho S474)+AKT1 (phospho S473) antibody (cat. no. ab192623; 1:2,000) were obtained from Abcam. The RevertAid First Strand cDNA Synthesis kit (cat. no. K1622), SuperSignal ${ }^{\mathrm{TM}}$ West Pico PLUS Chemiluminescent substrate (cat. no. 34580) and the SYBR ${ }^{\mathrm{TM}}$ Green PCR Master mix (cat. no. 4334973) were purchased from Thermo Fisher Scientific, Inc. The Cell Counting Kit-8 (CCK-8; cat. no. E606335) and the TUNEL apoptosis assay kits (cat. no. E607172) were purchased from Sangon Biotech Co., Ltd. Finally, the Annexin V-allophycocyanin (APC)/7'-aminoactinomycin D (AAD) Apoptosis Assay kit (cat. no. KGA1026) was obtained from Nanjing KeyGen Biotech Co., Ltd.

Cell culture and reagents. The human tongue squamous cell carcinoma cell line CAL-27 was obtained from the Central Laboratory of Yantai Yuhuangding Hospital of Qingdao University (Yantai, China). The cells were cultured in DMEM, supplemented with $10 \%$ FBS and $100 \mathrm{U} / \mathrm{ml}$ penicillin-streptomycin, and maintained in a humidified atmosphere at $37^{\circ} \mathrm{C}$ with $5 \% \mathrm{CO}_{2}$.

Adenovirus infection. The adenovirus vector (pAd-Track) was supplied by DrWang Shengzhi of Yantai Yuhuangding Hospital (Yantai, China) and the recombinant adenovirus expressing human IL-21 (Ad-IL-21) was constructed by Shanghai Shenggong Biology Engineering Technology Service, Ltd. Ad-IL-21 or Ad-null (pAd-Track null vector) were cloned into the adenovirus vector. When CAL-27 cells number reached $1 \times 10^{6}$, cells were infected with $1 \times 10^{8} \mu \mathrm{g}$ Ad-null or Ad-IL-21 by polybrene (Sigma) and the control cells were treated with PBS for $24 \mathrm{~h}$ at $37^{\circ} \mathrm{C}$.

Immunohistochemical (IHC) analysis. The expression levels of IL-21 were analyzed by IHC using standard staining procedures. Briefly, antigen retrieval was performed by incubating the sections in $10 \mathrm{mM}$ citric acid buffer ( $\mathrm{pH}$ 6.0) at $100^{\circ} \mathrm{C}$ for $15 \mathrm{~min}$. Subsequently, sections were dewaxed in xylene I and II at room temperature, for $20 \mathrm{~min}$ each, and rehydrated in a descending ethanol series (absolute ethanol for $5 \mathrm{~min}, 95 \%$ ethanol for $5 \mathrm{~min}, 90 \%$ ethanol for $5 \mathrm{~min}$ and $80 \%$ ethanol for $5 \mathrm{~min}$ ). Following three washes with PBS-Tween (0.05\% Tween-20 in PBS), the sections were incubated in 5\% BSA (Sangon Biotech Co., Ltd.) for $45 \mathrm{~min}$ at room temperature. The sections were subsequently incubated at $4^{\circ} \mathrm{C}$ overnight with rabbit anti-IL-21 polyclonal antibody diluted in 1X PBST (1:100). Following the primary antibody incubation, the membranes were washed in PBST and incubated with a HRP-conjugated goat anti-rabbit IgG secondary antibody (1:100) at room temperature for $45 \mathrm{~min}$. The slides were subsequently stained with 3,3'-diaminobenzidine tetrahydrochloride at room temperature for $10 \mathrm{~min}$. Finally, the sections were rehydrated with ethanol (80\% ethanol for $5 \mathrm{~min}$, $90 \%$ ethanol for $5 \mathrm{~min}$, 95\% ethanol for $5 \mathrm{~min}$ and absolute ethanol for $5 \mathrm{~min}$ ), cleared and mounted with neutral tree gum, and counterstained with $0.5 \%$ Harris' hematoxylin at room temperature for $5 \mathrm{~min}$. The images were screened using a confocal microscope (magnification, $\mathrm{x} 100$ and $\mathrm{x} 400$ ).

Western blotting. Total protein were extracted from cells or tissues using TNE lysis buffer $[1.0 \%$ (vol/vol) Triton X-100, $10 \mathrm{mM}$ Tris-HCl, pH 7.5, $120 \mathrm{mM} \mathrm{NaCl}, 25 \mathrm{mM} \mathrm{KCl}, 1 \mathrm{lg} / \mathrm{ml}$ leupeptin, $1 \mathrm{lg} / \mathrm{ml}$ pepstatin, $2 \mathrm{lg} / \mathrm{ml}$ aprotinin, and $0.5 \mathrm{mM}$ phenylmethylsulfonyl fluoride] (18). Total protein was quantified using the BCA method (19) and $30 \mu \mathrm{g}$ protein/lane was separated via SDS-PAGE on a $10 \%$ gel. The separated proteins were subsequently transferred onto PVDF membranes (Bio-Rad Laboratories, Inc.) and blocked in $10 \%$ non-fat milk in TBS-Tween $(0.05 \%$ Tween-20) at room temperature for $2 \mathrm{~h}$. The membranes were incubated with primary antibodies against: Polyclonal IL-21 (1:1,000); caspase-3 (1:2,000); Bax (1:2,000); Bcl-2 (1:1,000); JNK1+JNK2+JNK3 $(1: 2,000)$; JNK1+JNK2+JNK3 (phospho T183+T183+T221; 1:1,000); rabbit anti-AKT1+AKT2+AKT3 (1:1,000); AKT3 (phospho S472)+AKT2 (phospho S474)+AKT1 (phospho S473; $1: 2,000)$ and monoclonal $\beta$-actin $(1: 5,000)$ overnight at $4^{\circ} \mathrm{C}$. Following the primary antibody incubation, the membranes were incubated with HRP-conjugated goat anti-mouse $\operatorname{IgG}$ $(1: 3,000)$ and HRP-conjugated goat anti-rabbit IgG secondary antibodies $(1: 3,000)$ at room temperature for $1 \mathrm{~h}$. Protein bands were assessed using chemiluminescence substrates, which is an enhanced chemiluminescent HRP substrate that enables picogram to high femtogram-level protein detection (SuperSignal $^{\mathrm{TM}}$ West Pico PLUS Chemiluminescent substrate; Thermo Fisher Scientific, Inc.) and the expression levels were 
quantified using Image-Pro Plus software (version 6.0; Media Cybernetics, Inc.).

Reverse transcription-quantitative PCR (RT-qPCR). Total RNA was extracted from cells using TRIzol ${ }^{\circledR}$ reagent (Thermo Fisher Scientific, Inc.) according to the manufacturer's protocol. Total RNA was reverse transcribed into cDNA using the RevertAid First Strand cDNA Synthesis kit (Thermo Fisher Scientific, Inc.), according to the manufacturer's protocol. RT was performed as follows: $55^{\circ} \mathrm{C}$ for $30 \mathrm{~min}$, followed by $95^{\circ} \mathrm{C}$ for $5 \mathrm{~min}$ and $5^{\circ} \mathrm{C}$ for $5 \mathrm{~min}$. qPCR was subsequently performed using the SYBR ${ }^{\mathrm{TM}}$ Green PCR Master mix and a LightCycler ${ }^{\circledR} 480$ system (Thermo Fisher Scientific, Inc.), according to the manufacturer's protocols. The following primer sequences were used for qPCR: IL-21 forward, 5'-ATC CAGTCCTGGCAACATGG-3' and reverse, 5'-TGTGGCGAT CTTGACCTTGG-3'; and $\beta$-actin forward, 5'-CCACTGGCA TCGTGATGGAC-3' and reverse, 5'-ACGGATGTCCACGTC ACACT-3'. The following thermocycling conditions were used for qPCR: $95^{\circ} \mathrm{C}$ for $3 \mathrm{~min} ; 40$ cycles of $95^{\circ} \mathrm{C}$ for $30 \mathrm{sec}$, $60^{\circ} \mathrm{C}$ for $30 \mathrm{sec}, 72^{\circ} \mathrm{C}$ for $45 \mathrm{sec}$; and a final extension at $72^{\circ} \mathrm{C}$ for $1 \mathrm{~min}$. Expression levels were quantified using the $2^{-\Delta \Delta \mathrm{Cq}}$ method (20) and normalized to $\beta$-actin.

Cell viability assay. The infected CAL-27 cells were plated into 96-well plates at a density of $5 \times 10^{4}$ and cultured for $48 \mathrm{~h}$. Cell viability was measured using the CCK-8 assay kit (Sangon Biotech Co., Ltd.), according to the manufacturer's protocol. Briefly, the cells were washed with DMEM and incubated with $10 \mu \mathrm{l} \mathrm{CCK}-8$ solution at $37^{\circ} \mathrm{C}$ for $4 \mathrm{~h}$. Subsequently, the absorbance was measured at $450 \mathrm{~nm}$ with a spectrophotometer (BioTek Instruments, Inc.).

Cell migration assay. The infected CAL-27 cells were plated into $10 \mathrm{~cm}$ dish at a density $5 \times 10^{6}$ and cultured for $24 \mathrm{~h}$. Subsequently, the cells were scraped with a $200-\mu 1$ pipette tip and washed with PBS three times, prior to being cultured in DMEM without FBS. The images of the scratch wounds were captured at 0 or $24 \mathrm{~h}$ using a confocal microscope (magnification, $x 400)$. The width of each wound was quantified using Image-Pro Plus 6.0 software (Media Cybernetics, Inc.). The cell migration rate (\%) was calculated as follows: [(Width of wound at $0 \mathrm{~h}$-width of wound at $24 \mathrm{~h}$ )/width of wound at $0 \mathrm{~h}$ ] $\mathrm{x} 100 \%$.

TUNEL staining. The infected CAL-27 cells were plated into 6 -well plates dish at a density $2 \times 10^{5}$ and cultured for $48 \mathrm{~h}$. The TUNEL assay was performed using a TUNEL apoptosis assay kit, according to the manufacturer's protocol. Briefly, the cells were fixed in $4 \%$ paraformaldehyde at room temperature for $30 \mathrm{~min}$, permeabilized in $0.5 \%$ Triton X-100 on ice for $2 \mathrm{~min}$ and incubated with a dUTP and TDT enzyme reaction mixture in a humidified atmosphere at $37^{\circ} \mathrm{C}$ for $60 \mathrm{~min}$. Subsequently, the slides were incubated with streptavidin-fluorescein at $37^{\circ} \mathrm{C}$ for $30 \mathrm{~min}$ and counterstained with $5 \mu \mathrm{g} / \mathrm{ml}$ DAPI at room temperature for $5 \mathrm{~min}$. The slices were mounted with neutral tree gum. TUNEL-positive cells were observed in $\geq 5$ randomly selected fields of view using a fluorescent microscope (Bio-Rad Laboratories, Inc.; magnification, x400). The positive cells generated a bright green fluorescence.
A

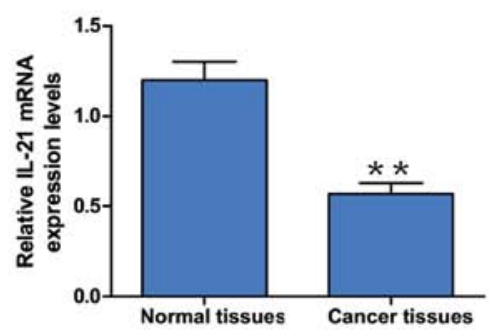

B

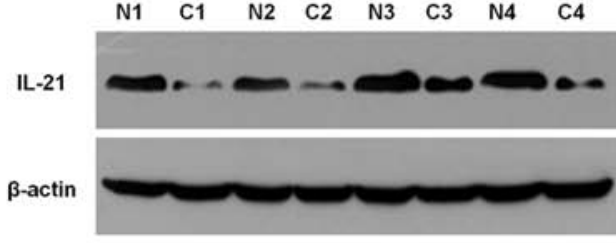

C

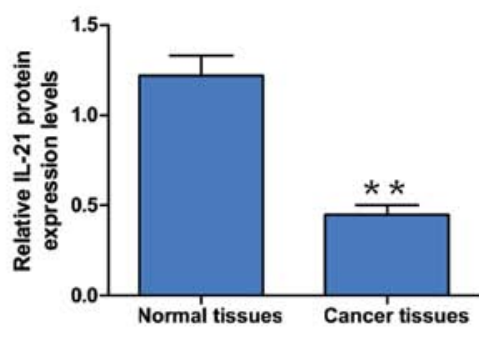

D

Normal tissues oscc tissues
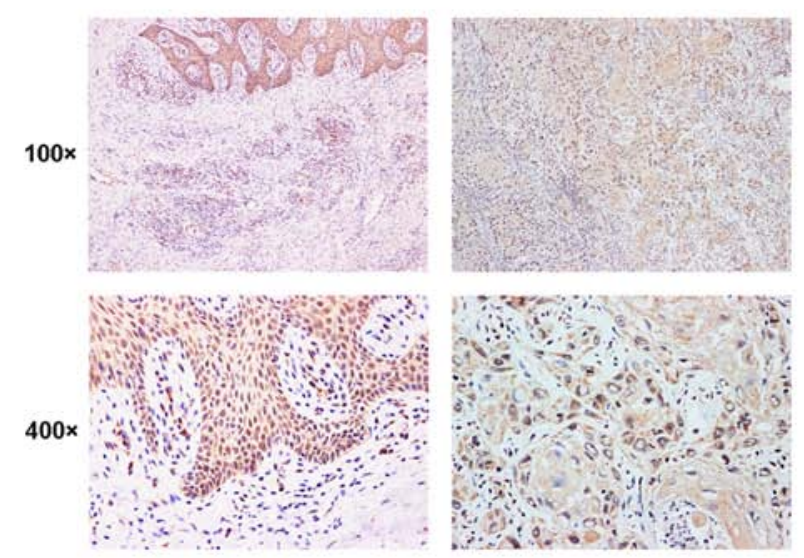

Figure 1. Expression levels of IL-21 in OSCC tissues. (A) mRNA expression levels of IL-21 in OSCC tissues and adjacent normal tissues were detected using reverse transcription-quantitative PCR. (B) Protein expression levels of IL-21 in OSCC tissues and adjacent normal tissues were detected using western blotting. (C) Semi-quantification of the western blotting data presented in part B. Expression levels of IL-21 were normalized to $\beta$-actin. The data are presented as the mean \pm SEM from three independent experiments. ${ }^{* *} \mathrm{P}<0.01$ vs. the normal tissues. (D) Representative immunohistochemistry images of IL-21 expression levels in OSCC tissues and adjacent normal tissues. Magnification, x100 or x400. IL-21, interleukin-21; OSCC, oral squamous cell carcinoma; N, Normal tissues; C, cancer tissues.

Flow cytometric analysis of apoptosis. Briefly, the infected cells $\left(5 \times 10^{5}\right.$ cells/well) were harvested with $0.25 \%$ trypsinization and centrifugated at $300 \mathrm{x}$ g for $5 \mathrm{~min}$ at room temperature, then rinsed twice with PBS and resuspended in $500 \mu$ l binding buffer solution at a density of $1 \times 10^{5}$ cells $/ \mathrm{ml}$. The cells were subsequently stained with $5 \mu \mathrm{l}$ Annexin V-APC and $5 \mu 1$ 7-AAD using the Annexin V-APC/AAD Apoptosis Assay kit at room temperature for $15 \mathrm{~min}$ in the dark, according to 
Table I. Association between interleukin-21 expression and the clinical and histopathological features of patients with oral squamous cell carcinoma $(n=45)$.

\begin{tabular}{|c|c|c|c|c|c|}
\hline Variables & Total number of patients, $\mathrm{n}$ & Positive & Positive rate (\%) & $\chi^{2}$ & P-value \\
\hline \multicolumn{6}{|l|}{ Sex } \\
\hline Male & 29 & 17 & 58.62 & \multirow[t]{2}{*}{0.024} & \multirow[t]{2}{*}{0.878} \\
\hline Female & 16 & 9 & 56.25 & & \\
\hline \multicolumn{6}{|l|}{ Age, years } \\
\hline$\geq 60$ & 24 & 14 & 58.33 & \multirow[t]{2}{*}{0.007} & \multirow[t]{2}{*}{0.936} \\
\hline$<60$ & 21 & 12 & 57.14 & & \\
\hline \multicolumn{6}{|l|}{ Tumor size, cm } \\
\hline$\geq 3$ & 24 & 13 & 54.17 & \multirow[t]{2}{*}{0.275} & \multirow[t]{2}{*}{0.600} \\
\hline$<3$ & 21 & 13 & 61.90 & & \\
\hline \multicolumn{6}{|l|}{ TNM stage } \\
\hline I or II & 14 & 13 & 92.85 & \multirow[t]{2}{*}{8.270} & \multirow[t]{2}{*}{$0.004^{\mathrm{b}}$} \\
\hline III or IV & 31 & 13 & 41.94 & & \\
\hline \multicolumn{6}{|l|}{ Differentiation } \\
\hline Well & 13 & 11 & 84.62 & \multirow[t]{2}{*}{3.961} & \multirow[t]{2}{*}{$0.047^{\mathrm{a}}$} \\
\hline Moderate/poor & 32 & 15 & 46.87 & & \\
\hline \multicolumn{6}{|c|}{ Lymph node metastasis } \\
\hline Negative & 12 & 11 & 91.67 & \multirow[t]{2}{*}{5.926} & \multirow[t]{2}{*}{$0.015^{\mathrm{a}}$} \\
\hline Positive & 33 & 15 & 45.45 & & \\
\hline
\end{tabular}

${ }^{\mathrm{a}} \mathrm{P}<0.05 .{ }^{\mathrm{b}} \mathrm{P}<0.01$.

the manufacturer's protocol. Apoptotic cells were analyzed using a CytoFLEX flow cytometer and CytExpert software (version 2.0; Beckman Coulter, Inc.) within $1 \mathrm{~h}$.

Statistical analysis. Statistical analysis was performed using SPSS 19.0 software (IBM Corp.). Data are presented as the mean \pm standard deviation, and all experiments were performed in triplicate. Statistical differences between the groups were analyzed with the paired Student's t-test or a one-way ANOVA, followed by a Tukey's post hoc test for multiple comparisons. A $\chi^{2}$ test was used to determine the association between the expression levels of IL-21 and OSCC clinical and histopathological features. $\mathrm{P}<0.05$ was considered to indicate a statistically significant difference.

\section{Results}

IL-21 expression levels are decreased in OSCC tissues. The expression levels of IL-21 in OSCC and adjacent normal tissues were analyzed using RT-qPCR and western blotting. The results indicated that both the mRNA and protein expression levels of IL-21 were significantly decreased in OSCC tissues compared with the adjacent normal tissues (Fig. 1A-C). Furthermore, IHC analysis was performed to analyze IL-21 expression levels; the positive rate of IL-21 detection was 20\% (9/45) in OSCC tissues and 62\% $(28 / 45)$ in the adjacent tissues (Fig. 1D). The positive rate of IL-21 detection decreased in the OSCC tumor tissue compared with the adjacent normal tissues (Fig. 1D). The associations between the expression levels of IL-21 and the clinicopathological features of OSCC are presented in Table I. IL-21-negative tumors were significantly associated with the TNM status, pathological grade and lymphocytic infiltration (Table I). Overall, these findings indicated that IL-21 expression levels may be decreased in OSCC tissues, which may be positively associated with the malignant progression of OSCC.

IL-21 inhibits the proliferation and migration of OSCC cells in vitro. To verify the roles of IL-21 in OSCC, a recombinant Ad was constructed to overexpress IL-21 (Ad-IL-21), which was used to infect CAL-27 cells in vitro. Initially, the expression levels of IL-21 mRNA and protein were analyzed using RT-qPCR (Fig. 2A) and western blotting respectively (Fig. 2B and C) to demonstrate the proof of successful infection. The results demonstrated that Ad-IL-21 infection significantly increased the mRNA and protein expression levels of IL-21 compared with the control and Ad-null cells (Fig. 2A-C). Subsequently, cell proliferation was analyzed using the CCK-8 method. The Ad-IL-21 group exhibited a significant decrease in cell viability compared with the control or the Ad-null group (Fig. 3A). Thus, it was suggested that IL-21 overexpression may inhibit the proliferation of CAL-27 cells. Furthermore, the role of IL-21 in cell migration was confirmed using a wound-healing assay. The results revealed that the cell migratory activity of the Ad-IL-21 group was significantly decreased at $24 \mathrm{~h}$ compared with the control or the Ad-null groups (Fig. 3B and C). Therefore, these results revealed that IL-21 overexpression may inhibit the proliferation and migration of CAL-27 cells in vitro. 

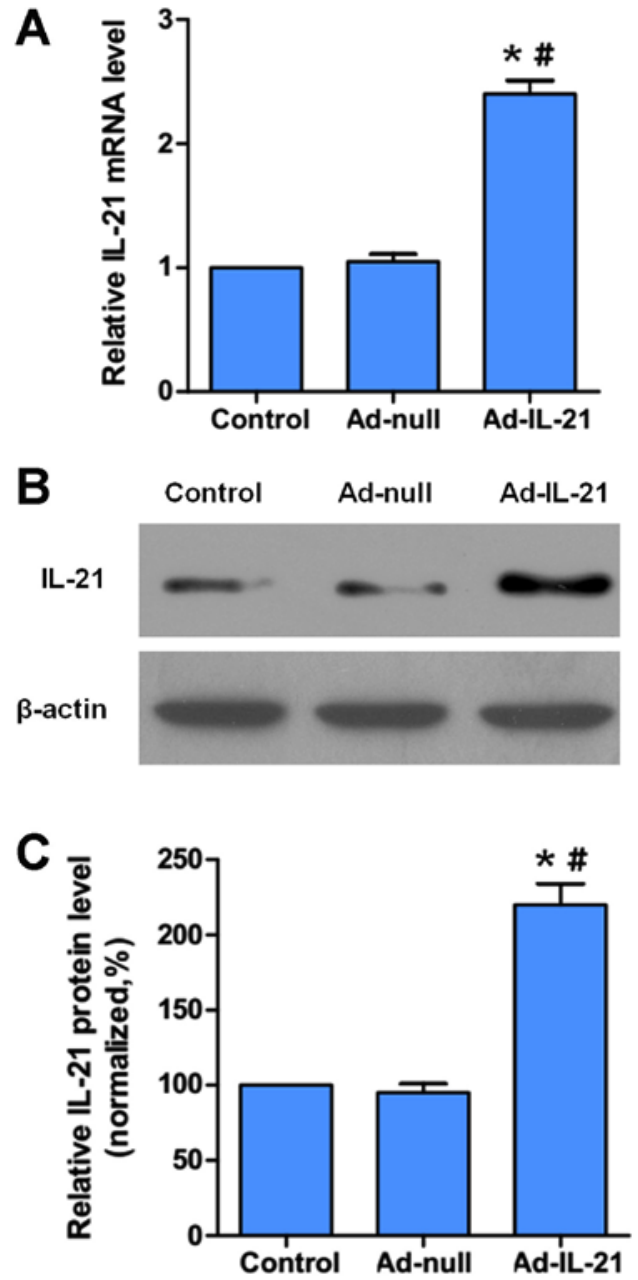

Figure 2. Adenoviral-mediated overexpression of IL-21 in CAL-27 cells. (A) Reverse transcription-quantitative PCR or (B) western blotting was used to analyze the mRNA or protein expression levels, respectively, of IL-21 in CAL-27 cells infected with Ad-null or Ad-IL-21. (C) Semi-quantification of the western blotting data presented in part B. Expression levels of IL-21 were normalized to $\beta$-actin. The data were expressed as the mean \pm SEM from three independent experiments. ${ }^{*} \mathrm{P}<0.05$ vs. the control group; ${ }^{*} \mathrm{P}<0.05$ vs. the Ad-null group. IL-21, interleukin-21; Ad, adenovirus.

IL-21 induces the apoptosis of OSCC cells in vitro. TUNEL staining was performed to determine the role of IL-21 in cell apoptosis. The number of apoptotic cells was significantly increased in the Ad-IL-21 group compared with the control or Ad-null groups (Fig. 4A and B). In addition, the expression levels of the pro-apoptotic proteins, c-caspase- 3 and Bax, and the anti-apoptotic protein $\mathrm{Bcl}-2$, were investigated. Western blotting indicated that the overexpression of IL-21 could significantly increase the expression levels of c-caspase- 3 and $\mathrm{Bax}$, while decrease the expression levels of $\mathrm{Bcl}-2$, and also significantly increase the $\mathrm{Bax} / \mathrm{Bcl}-2$ ratio compared with the control and Ad-null groups (Fig. 4C and D). Apoptosis was also investigated using flow cytometric analysis (Fig. 5); the number of apoptotic cells in the Ad-IL-21 group was significantly increased compared with the control or Ad-null groups. These results suggested that IL-21 may promote the apoptosis of CAL-27 cells in vitro.

IL-21 inhibits the activation of the JNK signaling pathway. To determine the molecular mechanism of IL-21 in CAL-27 cells,

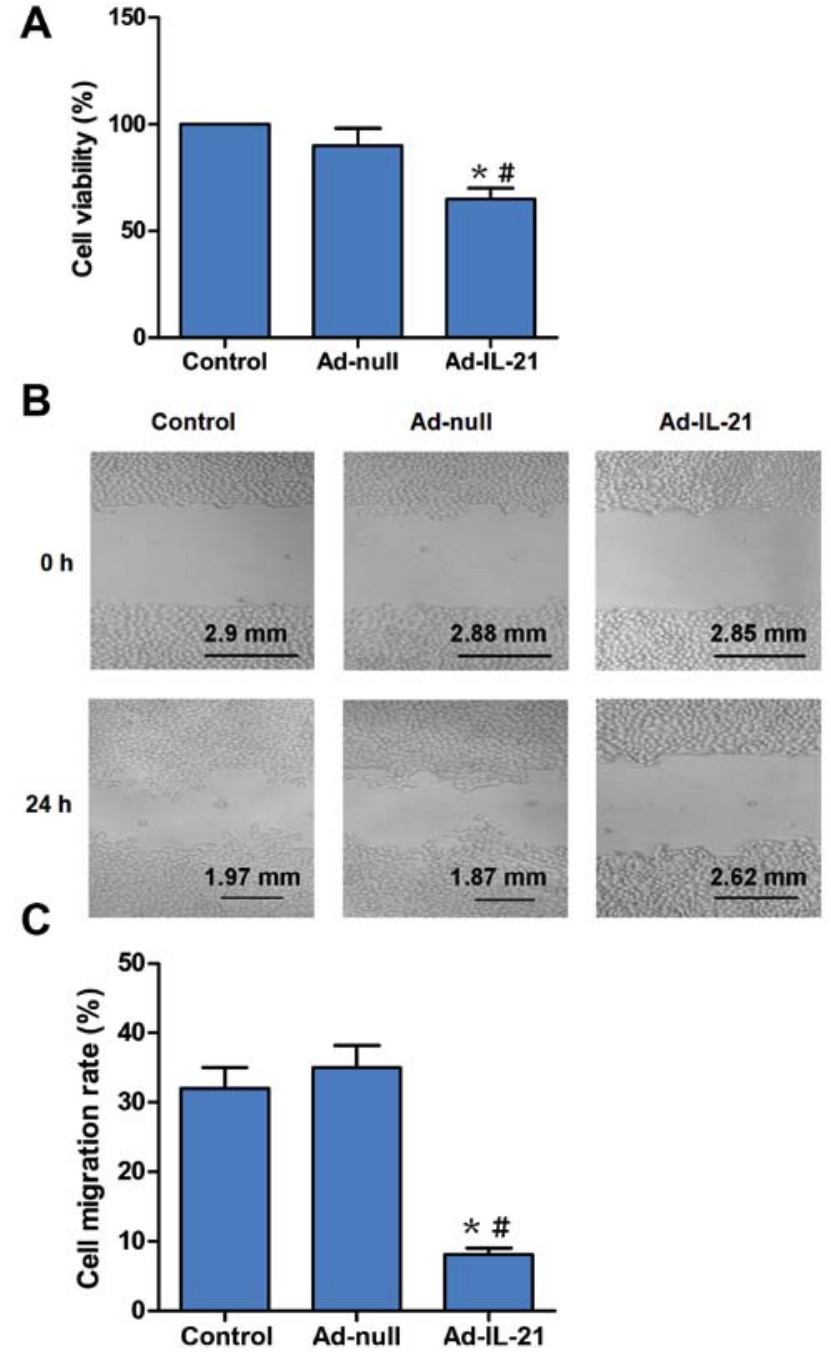

Figure 3. IL-21 inhibits the proliferation and migration of CAL-27 cells (A) Cell viability was measured using a Cell Counting Kit-8 assay in CAL-27 cells infected with Ad-null or Ad-IL-21. The value of the control group was set to $100 \%$ and the values of the other groups were normalized to the control group. (B) Cell migration was assessed using a wound healing assay in CAL-27 cells infected with Ad-null or Ad-IL-21. Magnification, x400. (C) Semi-quantification of the cell migration rate (\%) from part B. Data are expressed as the mean \pm SEM from three independent experiments. ${ }^{*} \mathrm{P}<0.05$ vs. the control group; ${ }^{\prime} \mathrm{P}<0.05$ vs. the Ad-null group. Il-21, interleukin-21; Ad, adenovirus.

the activation of JNK and AKT was analyzed using western blotting. The results indicated that IL-21 overexpression significantly decreased the phosphorylation levels of JNK compared with the control and Ad-null groups (Fig. 6A and B), but had no effect on the phosphorylation levels of AKT (Fig. 6C and D). Therefore, the inhibitory effect of IL-21 in CAL-27 cells may function through the JNK signaling pathway.

\section{Discussion}

The $\mathrm{CD}^{+} \mathrm{T}$-cell population is the main source of IL-21 (21); within this population, $\mathrm{T}$ follicular helper cells and Th17 cells have been found to produce the highest amounts of IL-21, whereas the production from NK cells was observed to be slightly lower (21). However, IL-21 has been revealed to be an important regulator of the differentiation, proliferation, 
A

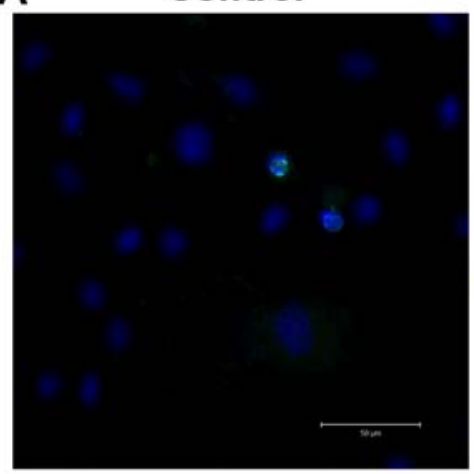

B

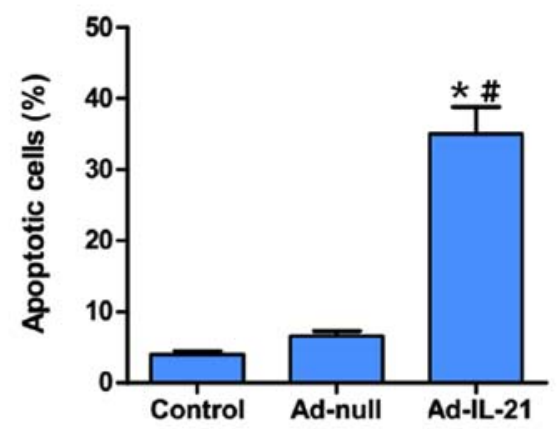

Ad-null

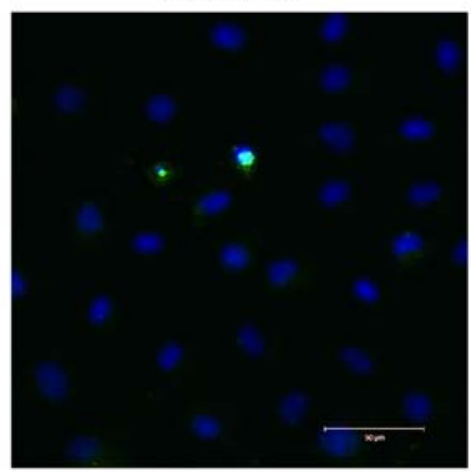

Ad-IL-21

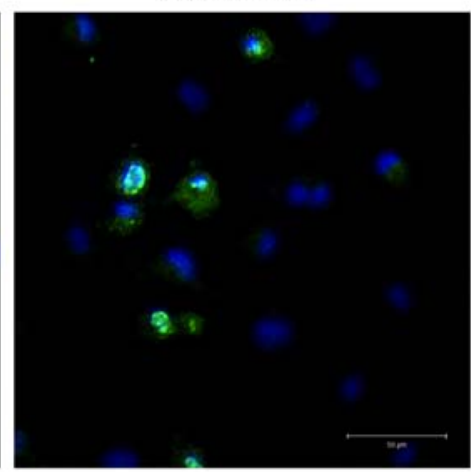

C

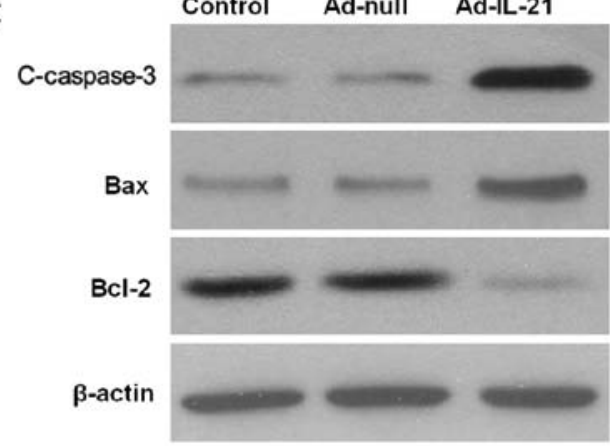

D

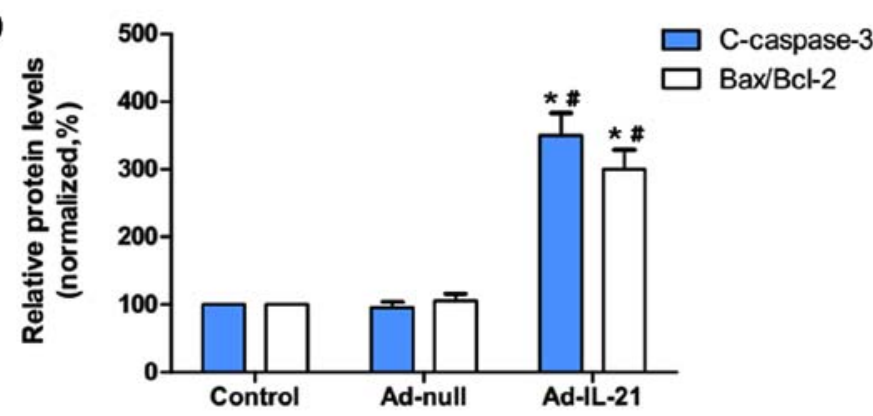

Figure 4. IL-21 induces the apoptosis of CAL-27 cells. (A) CAL-27 cells were infected with Ad-null or Ad-IL-21 and TUNEL staining was performed. Scale bar, $50 \mu \mathrm{m}$. (B) Percentage of TUNEL-positive cells was semi-quantified to determine the percentage rate of apoptosis. (C) Western blotting was used to analyze the expression levels of the pro-apoptotic proteins, c-caspase-3 and Bax, and the anti-apoptotic protein, Bcl-2 in CAL-27 cells infected with Ad-null or Ad-IL-21. (D) Semi-quantification of the expression levels of c-caspase-3 and the Bax/Bcl-2 ratio from part C. Expression levels were normalized to $\beta$-actin. The data are presented as the mean \pm SEM from three independent experiments. ${ }^{*} \mathrm{P}<0.05$ vs. the control group; ${ }^{*} \mathrm{P}<0.05$ vs. the Ad-null group. IL-21, interleukin-21; Ad, adenovirus; c-, cleaved.

survival and activation of NK cells (22-24). IL-21 reportedly serves multiple functions, such as lymphocytes proliferation, cytotoxicity of CD8+ T cells and natural killer (NK) cells, B-cell differentiation and Th17 development, in multiple lymphoid organs and myeloid populations, in addition to within epithelial cells (25). Recently, the therapeutic efficacy of IL-21 as single-agent immunotherapy has been tested in phase I and II clinical trials to treat different types of cancers including melanoma, renal cell carcinoma and metastatic colorectal cancer (13). A modest clinical outcome was observed when patients with stage IV malignant melanoma who did not receive prior treatment were treated with IL-21 at a dose of $30 \mathrm{mg} / \mathrm{kg} / \mathrm{d}$ in 5-day cycles. The overall response rate of this study according to RECIST was about $8 \%$, with one of 14 patients achieving a complete response and one patient having a confirmed partial response (26). Current research is focusing on the potential of IL-21 in combination with targeted therapy. Such as cetuximab, an antibody of epidermal growth factor receptor (EGFR) (27). In a phase I trial, the combination of IL-21 and cetuximab achieved the best response in $60 \%$ of patients with stage IV colorectal cancer (28). However, IL-21 appears to have a major role in promoting the inflammation-induced development of colon cancer, thus the aforementioned clinical trial was terminated (28).

In the present study, IL-21 expression levels were detected in the OSCC tissues and the results revealed that IL-21 expression levels were significantly decreased in OSCC tissues, which was closely associated with the clinical stage of the tumor and lymph node metastasis. These findings suggested that the expression of IL-21 may be defective during tumor progression. Consistent with these results, Dutta et al (29) also reported that the levels of IL-21 mRNA transcripts decreased in OSCC tissues and a similar trend of transcript expression of IL-21 was also observed in peripheral blood 

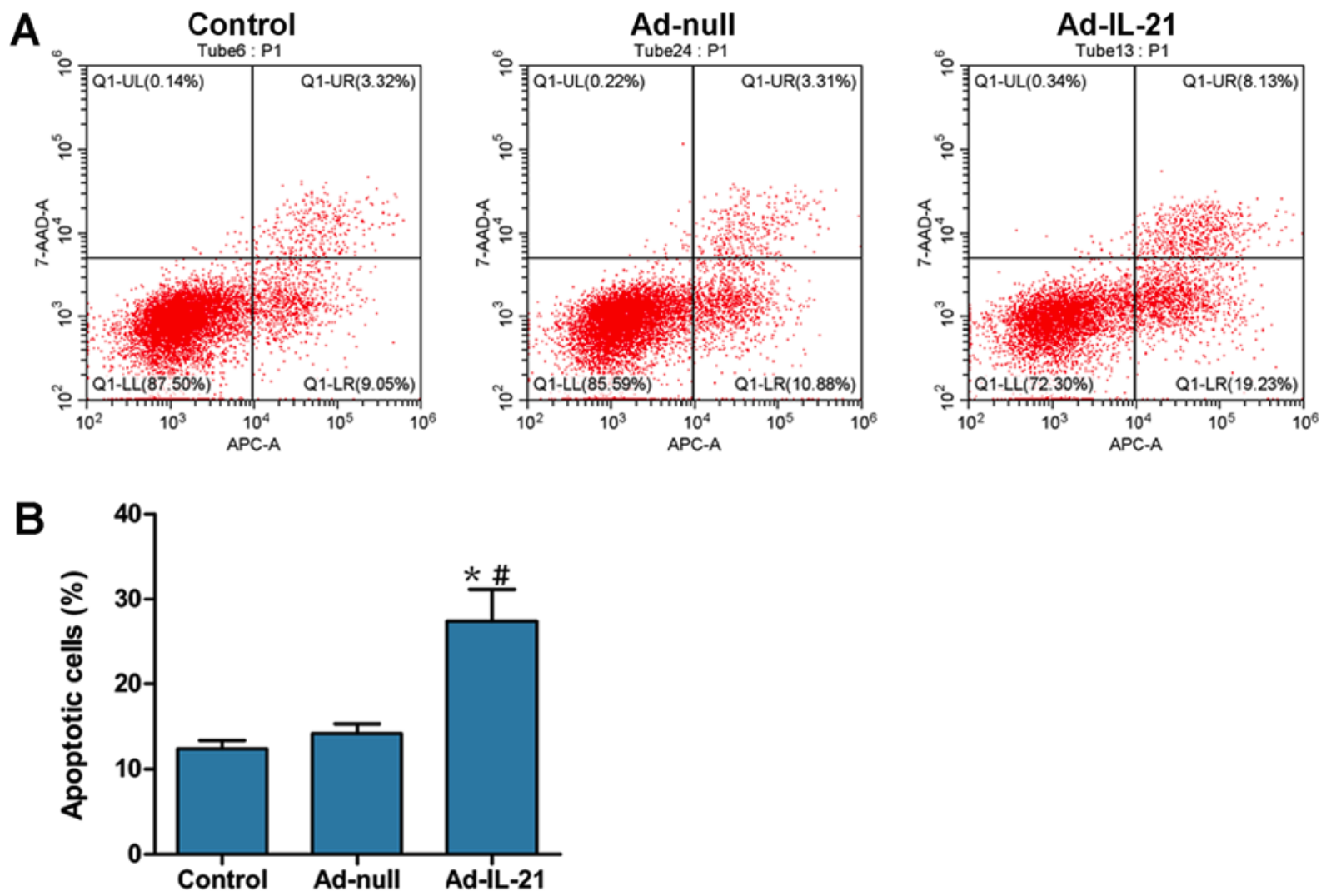

Figure 5. IL-21 can induce the apoptosis of CAL-27 cells. (A) CAL-27 cells were infected with Ad-null or Ad-IL-21 and flow cytometry was performed. (B) Semi-quantification of the apoptotic data from part A. The data are presented as the mean \pm SEM from three independent experiments. ${ }^{*} \mathrm{P}<0.05$ vs. the control group; " $\mathrm{P}<0.05$ vs. the Ad-null group. IL-21, interleukin-21; Ad, adenovirus; APC, allophycocyanin; ADD, 7'-aminoactinomycin D.
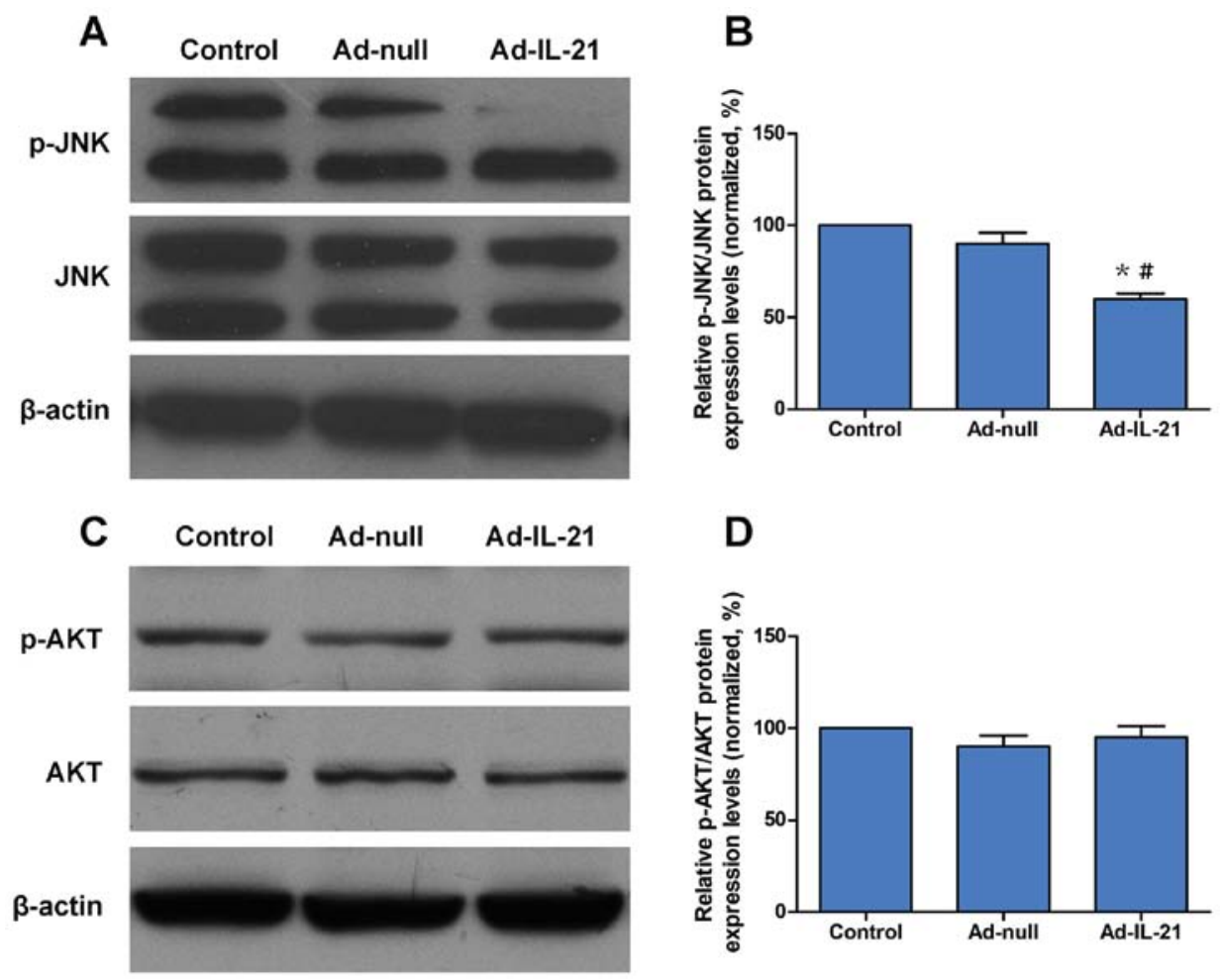

Figure 6. IL-21 inhibits the activation of the JNK signaling pathway. (A) Western blotting was used to analyze the expression levels of JNK and p-JNK in CAL-27 cells infected with Ad-null or Ad-IL-21. (B) Semi-quantification of the expression levels of p-JNK/JNK from part A. Expression levels were normalized to $\beta$-actin. (C) Western blotting was used to analyze the expression levels of AKT and p-AKT in CAL-27 cells infected with Ad-null or Ad-IL-21. (D) Semi-quantification of the expression levels of p-AKT/AKT from part C. Expression levels were normalized to $\beta$-actin. The data are expressed as the mean \pm SEM from three independent experiments. ${ }^{*} \mathrm{P}<0.05$ vs. the control group; ${ }^{*} \mathrm{P}<0.05$ vs. the Ad-null group. IL-21, interleukin-21; Ad, adenovirus; p-, phosphorylated. 
of patients with OSCC. Subsequently, the role of IL-21 on the proliferation, migration and apoptosis of OSCC cells was investigated in vitro. IL-21 overexpression was revealed to inhibit cell proliferation and migration, whilst promoting cell apoptosis in CAL-27 cells. Another study on laryngeal cancer cells also demonstrated that when IL-21 was overexpressed in Hep-2 cells, the proliferation and invasion of Hep-2 cells decreased (30). In hepatocellular carcinoma (HCC), exogenous IL-21 may reinvigorate NK cells in patients with $\mathrm{HBV}$-associated $\mathrm{HCC}$, resulting in significantly increased levels of cytotoxicity, degranulation and cytokine expression, and the reinvigoration of NK function by IL-21 is mediated by the STAT1 signaling pathway (31). In various solid and hematological tumors, IL-21 improves effector $\mathrm{T}$ cell and NK cell cytotoxic activity and IL-21 was also discovered to inhibit cancer cell viability by stimulating interferon- $\gamma$ production and by increasing the granularity of NK cells $(32,33)$. Therefore, IL-21 may be an effective agent for cancer immunotherapy (34).

In conclusion, the present study indicated that IL-21 may exert a potent inhibitory effect over OSCC growth in vitro. Future studies should aim to investigate the role of IL-21 in OSCC animal models in order to determine its potential as an immunotherapeutic target for OSCC.

\section{Acknowledgements}

Not applicable.

\section{Funding}

This study was supported by grants from the Natural Science Foundation of Shandong Province (grant no. ZR2016HM72), the National Natural Science Foundation of China (grant no. 81701246) and the Medical and Health Development Program of Shandong Province (grant no. 2016WS0711).

\section{Availability of data and materials}

The datasets used and/or analyzed during the current study are available from the corresponding author on reasonable request.

\section{Authors' contributions}

HL and SW designed the study; HL, PL, DX and XW performed the experiments and analyzed the data; DS performed the immunohistochemical analysis and constructed the figures; and JY and SW collected the human OSCC samples, confirmed the histological grade and tumor stage and drafted the initial manuscript. All authors read and approved the final manuscript.

\section{Ethics approval and consent to participate}

Ethical approval was obtained from the Ethics Committee of the Yantai Yuhuangding Hospital (Yantai, China; approval no. 2015-127). All procedures performed in the study involving human participants were in accordance with the ethical standards of the Institutional and National Research
Committee and with the Declaration of Helsinki (1964) and its later amendments or comparable ethical standards $(35,36)$.

\section{Patient consent for publication}

The present study followed the tenets of the Declaration of Helsinki and informed written consent was obtained from all patients and control subjects following the explanation of the nature and possible consequences of the study.

\section{Competing interests}

The authors declare that they have no competing interests.

\section{References}

1. Bray F, Ferlay J, Soerjomataram I, Siegel RL, Torre LA and Jemal A: Global cancer statistics 2018: GLOBOCAN estimates of incidence and mortality worldwide for 36 cancers in 185 countries. CA Cancer J Clin 68: 394-424, 2018.

2. Ribeiro IL, de Medeiros JJ, Rodrigues LV, Valenca AM and Lima Neto Ede A: Factors associated with lip and oral cavity cancer. Rev Bras Epidemiol 18: 618-629, 2015.

3. Varoni EM, Lodi G and Iriti M: Ethanol versus phytochemicals in wine: Oral cancer risk in a light drinking perspective. Int J Mol Sci 16: 17029-17047, 2015.

4. Mascitti M, Orsini G, Tosco V, Monterubbianesi R, Balercia A, Putignano A, Procaccini M and Santarelli A: An overview on current non-invasive diagnostic devices in oral oncology. Front Physiol 9: 1510, 2018.

5. Polverini PJ, D'Silva NJ and Lei YL: Precision therapy of head and neck squamous cell carcinoma. J Dent Res 97: 614-621, 2018.

6. Dinesh P and Rasool M: Multifaceted role of IL-21 in rheumatoid arthritis: Current understanding and future perspectives. J Cell Physiol 233: 3918-3928, 2018.

7. Zuniga EI, Macal M, Lewis GM and Harker JA: Innate and adaptive immune regulation during chronic viral infections. Annu Rev Virol 2: 573-597, 2015.

8. Croce M, Rigo V and Ferrini S: IL-21: A pleiotropic cytokine with potential applications in oncology. J Immunol Res 2015: 696578, 2015.

9. Davis MR, Zhu Z, Hansen DM, Bai Q and Fang Y: The role of IL-21 in immunity and cancer. Cancer Lett 358: 107-114, 2015.

10. Chen C, Liu X and Ren Y: Interleukin 21 treatment in a murine model as a novel potential cytokine immunotherapy for colon cancer. Adv Clin Exp Med 27: 583-589, 2018.

11. Li L, Ma Y, Xu Y and Maerkeya K: TIM-3 expression identifies a distinctive PD-1(+) follicular helper T cell subset, with reduced interleukin 21 production and B cell help function in ovarian cancer patients. Int Immunopharmacol 57: 139-146, 2018.

12. Wang LN, Cui YX, Ruge F and Jiang WG: Interleukin 21 and its receptor play a role in proliferation, migration and invasion of breast cancer cells. Cancer Genomics Proteomics 12: 211-221, 2015.

13. Bhatia S, Curti B, Ernstoff MS, Gordon M, Heath EI, Miller WH Jr, Puzanov I, Quinn DI, Flaig TW, VanVeldhuizen P, et al: Recombinant interleukin-21 plus sorafenib for metastatic renal cell carcinoma: A phase 1/2 study. J Immunother Cancer 2: 2, 2014.

14. Bhatt S, Sarosiek KA and Lossos IS: Interleukin 21-its potential role in the therapy of B-cell lymphomas. Leuk Lymphoma 58: $17-29,2017$

15. Timmerman JM, Byrd JC, Andorsky DJ, Yamada RE, Kramer J, Muthusamy N, Hunder N and Pagel JM: A phase I dose-finding trial of recombinant interleukin-21 and rituximab in relapsed and refractory low grade B-cell lymphoproliferative disorders. Clin Cancer Res 18: 5752-5760, 2012.

16. Katabi $\mathrm{N}$ and Lewis JS: Update from the 4th edition of the world health organization classification of head and neck tumours: What is new in the 2017 WHO blue book for tumors and tumor-like lesions of the neck and lymph nodes. Head Neck Pathol 11: 48-54, 2017.

17. Head and Neck Cancer Study Group (HNCSG); Monden N Asakage T, Kiyota N, Homma A, Matsuura K, Hanai N, Kodaira T, Zenda S, Fujii H, et al: A review of head and neck cancer staging system in the TNM classification of malignant tumors (eighth edition). Jpn J Clin Oncol 49: 589-595, 2019. 
18. Sun ZP, Gong L, Huang SH, Geng Z, Cheng L and Chen ZY: Intracellular trafficking and secretion of cerebral dopamine neurotrophic factor in neurosecretory cells. J Neurochem 117: 121-132, 2011.

19. Olson B: Assays for determination of protein concentration. Curr Protoc Pharmacol 73: A 3A 1-A 3A 32, 2016.

20. Livak KJ and Schmittgen TD: Analysis of relative gene expression data using real-time quantitative PCR and the 2(-Delta Delta C(T)) method. Methods 25: 402-408, 2001.

21. Tangye SG and Ma CS: Regulation of the germinal center and humoral immunity by interleukin-21. J Exp Med 217: e20191638, 2020.

22. Gharibi T, Majidi J, Kazemi T, Dehghanzadeh R, Motallebnezhad M and Babaloo Z: Biological effects of IL-21 on different immune cells and its role in autoimmune diseases Immunobiology 221: 357-367, 2016.

23. Li Q, Ye LJ, Ren HL, Huyan T, Li J, Shi JL and Huang QS Multiple effects of IL-21 on human NK cells in ex vivo expansion. Immunobiology 220: 876-888, 2015.

24. Romee R, Leong JW and Fehniger TA: Utilizing cytokines to function-enable human NK cells for the immunotherapy of cancer. Scientifica (Cairo) 2014: 205796, 2014.

25. Spolski R and Leonard WJ: Interleukin-21: A double-edged sword with therapeutic potential. Nat Rev Drug Discov 13: 379-395, 2014.

26. Davis ID, Brady B, Kefford RF, Millward M, Cebon J, Skrumsager BK, Mouritzen U, Hansen LT, Skak K, Lundsgaard D, et al: Clinical and biological efficacy of recombinant human interleukin-21 in patients with stage IV malignan melanoma without prior treatment: A phase IIa trial. Clin Cancer Res 15: 2123-2129, 2009.

27. Kim N, Cho D, Kim H, Kim S, Cha YJ, Greulich H, Bass A Cho HS and Cho J: Colorectal adenocarcinoma-derived EGFR mutants are oncogenic and sensitive to EGFR-targeted monoclonal antibodies, cetuximab and panitumumab. Int J Cancer 146: 2194-2200, 2020.

28. Steele N, Anthony A, Saunders M, Esmarck B, Ehrnrooth E, Kristjansen PE, Nihlen A, Hansen LT and Cassidy J: A phase 1 trial of recombinant human IL-21 in combination with cetuximab in patients with metastatic colorectal cancer. Br J Cancer 106: 793-798, 2012.
29. Dutta A, Banerjee A, Saikia N, Phookan J, Baruah MN and Baruah S: Negative regulation of natural killer cell in tumor tissue and peripheral blood of oral squamous cell carcinoma. Cytokine 76: 123-130, 2015.

30. Yang Q, Qiao X, Li D, Chen B, Zhang L, Yuan C and Lin H: Expression and association of IL-21, FBXL20 and tumour suppressor gene PTEN in laryngeal cancer. Saudi J Biol Sci 26: 2048-2051, 2019

31. Jin Y, Sun Z, Geng J, Yang L, Song Z, Song H, Wang J and Tang J: IL-21 reinvigorates exhausted natural killer cells in patients with HBV-associated hepatocellular carcinoma in STAT1-depedent pathway. Int Immunopharmacol 70: 1-8, 2019.

32. Seo H, Jeon I, Kim BS, Park M, Bae EA, Song B, Koh CH, Shin KS, Kim IK, Choi K, et al: IL-21-mediated reversal of NK cell exhaustion facilitates anti-tumour immunity in MHC class I-deficient tumours. Nat Commun 8: 15776, 2017.

33. Leonard WJ, Lin JX and O'Shea JJ: The $\gamma$ c family of cytokines: Basic biology to therapeutic ramifications. Immunity 50 : 832-850, 2019.

34. Floros T and Tarhini AA: Anticancer cytokines: Biology and clinical effects of interferon- $\alpha 2$, interleukin (IL)-2, IL-15, IL-21, and IL-12. Semin Oncol 42: 539-548, 2015.

35. Bruce-Chwatt LJ: Declaration of helsinki. Recommendations guiding doctors in clinical research. WHO Chron 19: 31-32, 1965.

36. Woods S and McCormack P: Disputing the ethics of research: The challenge from bioethics and patient activism to the interpretation of the declaration of helsinki in clinical trials Bioethics 27: 243-250, 2013.

This work is licensed under a Creative Commons Attribution-NonCommercial-NoDerivatives 4.0 International (CC BY-NC-ND 4.0) License. 